2019-06

\title{
Characterisation of fatigue crack growth using digital image correlation measurements of plastic CTOD
}

Vasco-Olmo, JM

http://hdl.handle.net/10026.1/14754

10.1016/j.tafmec.2019.03.009

Theoretical and Applied Fracture Mechanics

Elsevier

All content in PEARL is protected by copyright law. Author manuscripts are made available in accordance with publisher policies. Please cite only the published version using the details provided on the item record or document. In the absence of an open licence (e.g. Creative Commons), permissions for further reuse of content should be sought from the publisher or author. 


\title{
Characterisation of fatigue crack growth using digital image correlation measurements of CTOD
}

\author{
J.M. Vasco-Olmo ${ }^{1 *}$, F.A. Díaz ${ }^{1}$, F.V. Antunes ${ }^{2}$, M.N. James ${ }^{3,4}$ \\ ${ }^{1}$ Departamento de Ingeniería Mecánica y Minera, University of Jaén, Jaén, Spain. \\ ${ }^{2}$ Department of Mechanical Engineering, University of Coimbra, Coimbra, Portugal. \\ ${ }^{3}$ School of Engineering, University of Plymouth, Plymouth, United Kingdom. \\ ${ }^{4}$ Department of Mechanical Engineering, Nelson Mandela Metropolitan University, Port Elisabeth, South Africa. \\ *corresponding author: jvasco@ujaen.es
}

\begin{abstract}
In this work an experimental study of the crack tip opening displacement (CTOD) is performed to evaluate the ability of this parameter to characterise fatigue crack growth. A methodology is developed to measure and to analyse the CTOD from experimental data. The vertical displacements obtained by implementing digital image correlation (DIC) on growing fatigue cracks are used to measure the CTOD. Fatigue tests at stress ratios of 0.1 and 0.6 were conducted on compact tension (CT) specimens manufactured from commercially pure titanium. A sensitivity analysis was performed to explore the effect of the position selected behind the crack tip for the CTOD measurement. The analysis of a full loading cycle allowed identifying the elastic $\left(\mathrm{CTOD}_{\mathrm{el}}\right)$ and plastic $\left(\mathrm{CTOD}_{\mathrm{p}}\right)$ components of the CTOD. The plastic CTOD was found to be directly related to the nonlinear zone (i.e., plastic deformation) generated at the crack tip during fatigue propagation. Moreover, a linear relationship between $d a / d N$ and $\Delta \mathrm{CTOD}_{\mathrm{p}}$ independent of the stress ratio was found. Results show that the CTOD can be used as a viable alternative to the stress intensity factor range $(\Delta K)$ in characterising fatigue crack propagation since the parameter considers the fatigue threshold and crack shielding in an intrinsic way.
\end{abstract}

Keywords: Crack tip opening displacement, fatigue crack growth, DIC, plastic deformation. 


\section{Introduction}

Under nominally small-scale yielding conditions, where the extent of nonlinear plastic deformation at the tip of a growing fatigue crack is small enough that the overall response of the body remains elastic, the crack growth rate can be related to the applied stresses using the socalled Paris 'law' where the characterising parameter is the range of elastic stress intensity factor $[1,2]$. Although the Paris law provides a useful and successful characterisation of fatigue crack growth rate in many engineering applications it suffers from the major deficiency of being purely empirical, and hence provides no fundamental insight into the mechanisms of fatigue crack propagation.

This point was noted by Hosseini et al [3] and has led to ongoing difficulties in situations where the LEFM similitude concept breaks down, in particular in situations where fatigue crack closure or crack tip shielding mechanisms operate. The CJP model for crack tip stress and displacement fields [4-6] deals with this problem of lack of physical insight by defining a modified set of stress intensity factors that directly characterise the effective driving force for fatigue crack growth in the presence of a plastic enclave surrounding the growing fatigue crack. These incorporate several effects of the plasticity-induced forces acting at the elastic-plastic boundary, e.g. crack wake contact and compatibility-induced shear stresses acting in the plane of the crack. This approach has proven to be very useful in quantifying plastic zone size and shape [7] and in better rationalising fatigue crack growth rate data across different specimen geometries and stress ratios [8].

Ritchie and co-workers provide a very useful summary of the various more analytical attempts at modelling fatigue crack growth rate [3], pointing out that a sound description of the stress and strain fields ahead of a propagating fatigue crack, based on appropriate constitutive equations, has been lacking (the CJP model is a crack-tip field model that incorporates elastic stresses induced by the plastic enclave and does not consider the overall constitutive relationships). Reference [3] goes on to derive a constitutive law for cyclic plasticity and then use finite element modelling to calculate the plasticity-driven crack propagation rate under cyclic loading. They calculate the steady-state growth rate $d a / d N$ by considering the change in location of the crack tip during a load cycle, with the magnitude of the growth rate reflecting the plastic state of the material ahead of the crack tip and the associated plastic energy dissipation. Their work provides an underpinning constitutive model for the use of crack-tip opening displacement (CTOD) to characterise fatigue crack growth rate. The CTOD parameter was originally proposed by Wells [9] and Burdekin and Stone [10] as a more physically-based explanation for crack extension processes that could also 
be related to the crack-tip blunting explanation of fatigue crack growth and striation formation given by Laird and Smith [11].

a mere perturbation in an otherwise elastic material, Paris et al. [1], [2] postulated that the propagation of a crack under cyclic loading could be governed by an empirical relationship traditionally known as 'Paris law'. This 'law' relates the change in the length of the fatigue crack per load cycle $(d a / d N)$ to the stress intensity factor range $(\Delta K)$. However, although the procedures for analysing constant amplitude fatigue under small-scale yielding conditions are fairly well established, there are several controversial issues and unanswered questions in this field, remaining a number of uncertainties. Variable amplitude loading, large-scale plasticity or short cracks, among others, introduce additional complications that are not fully understood.

According to this, linear elastic fracture mechanics (LEFM) is valid only as long as nonlinear material deformation is confined to a small region surrounding the crack tip. In addition, in many materials it is virtually impossible to characterise the fracture behaviour with LEFM, and an alternative fracture mechanics model is required. Elastic-plastic fracture mechanics (EPFM) is applied to materials that exhibit extensive nonlinear behaviour (i.e., significant plastic deformation). Hence the linear elastic parameter $\Delta K$ should be replaced by a nonlinear crack tip parameter since fatigue crack growth is governed by nonlinear processes at the crack tip. Two main elastic-plastic parameters have been proposed to be related with crack tip plastic deformation, the crack tip opening displacement (CTOD) and the $J$ contour integral. Both parameters describe crack tip conditions in elastic-plastic materials and they can be used as crack driving parameters. CTOD is a local parameter, while the $J$-integral is used as a global criterion based on the energy release rate. There are limits to the applicability of CTOD and $J$-integral, but these limits are much less restrictive than the validity requirements of LEFM. In this work, the CTOD is the nonlinear parameter used to characterise fatigue crack growth.

The stress intensity factor provides a unique characterisation of the near-tip fields under smallscale yielding conditions, while the corresponding loading parameter for the characterisation of nonlinear behaviour is the $J$-integral proposed by Rice [3]. Although some of the features of this integral were embedded in the energy concepts derived by Eshelby [4] and were discussed independently by Sanders [5] and Cherepanov [6], the particular form of this line integral proposed by Rice [3] has led to the unifying theoretical basis for nonlinear fracture mechanics. The experimental work on the use of the cyclic $J$-integral to characterise fatigue crack growth reported in the literature dates between the 70s and the 90s. Nowadays, researchers on this topic are more focused in exploring it from a numerical point of view. Dowling and Begley [7] applied the $J$-integral to characterise fatigue crack growth under large-yielding conditions where $K$ is no 
longer valid.They proposed a power law similar to that previously reported by Paris et al. [1] but based on the cyclic $J$-integral $\Delta J$. The cyclic loading was applied under displacement control on compact tension specimens of A533B steel. Sadananda and Shahinian [8] developed a selfconsistent procedure for the evaluation of the $J$-integral parameter for load-controlled fatigue at high temperature using precracked compact tension specimens. The authors observed that their developed procedure had a broader applicability than the linear elastic parameter. Mowbray [9] used the cyclic $J$-integral to study fatigue crack growth in $\mathrm{Cr}-\mathrm{Mo}-\mathrm{V}$ steel at high-rate regime. They observed that the growth occurred under essentially constant $\Delta J$. El-Haddad and Mukherjee [10] performed a study on fatigue crack growth rate on ASTM A516 grade 70 steel subjected to elastic and elastic-plastic cyclic loading for both load-controlled and displacement-controlled test conditions. The cyclic $J$-crack growth rate data agreed well with that from the linear elastic tests. In addition, the $J$-integral parameter was shown to be better than the linear elastic parameter $K$ in correlating fatigue crack growth at high-load levels. Jolles [11] implemented the cyclic $J$-integral to characterise fatigue crack growth on A533B steel when plasticity effects are important. They observed that for both increasing and decreasing load gradients, $\Delta J$ may be employed to correlate fatigue data. Banks-Sills and Volpert [12] developed an experimental/numerical study of the cyclic $J$-integral in order to more clearly explain the meaning of this parameter for fatigue crack growth studies. They performed constant amplitude fatigue tests at two $R$-ratios ( 0.05 and 0.5$)$ on compact tension specimens manufactured from Al2024-T351.

CTOD was first observed by Wells [13] when he was attempting to measure the fracture toughness value in a number of structural steels. He found that these materials were too tough to be characterised by LEFM. While examining fractured test specimens, Wells noticed that the crack surfaces had moved apart prior to fracture. Plastic deformation had blunted an initially sharp crack, resulting in a finite displacement at the crack tip. The degree of crack blunting increased in proportion to the toughness of the material. This observation led Wells to propose the opening at the crack tip as a measurement of fracture toughness. Since long time ago, CTOD has been considered as a classical parameter in EPFM and it has been also used to experimentally characterise fatigue crack growth. Laird and Smith [14] used the crack tip blunting at maximum load and the crack tip re-sharpening at minimum load to explain fatigue crack growth. Pelloux [15] developed a comparison of the slip line flow field at the tip for both a sharp and a blunted crack by electron fractography. They observed that a sharp crack could be extended by alternating shear until it became blunted and that crack propagation was the result of repeated cyclic crack extension by alternating shear. Donahue et al. [16] reported that fatigue crack growth for different materials could be accurately described in terms of the mechanical properties and two material constants by using a direct proportionality between the rate of fatigue crack growth and COD above a threshold. Nicholls [17] assumed a polynomial relation between crack blunting and crack 
extension to derive an expression for the rate of fatigue crack growth. The expression obtained accurately predicted fatigue crack growth rates for a wide variety of titanium, nickel, aluminium and steel alloys. Weidner et al. [18] investigated the influence of different overstraining events on the COD of microstructurally short cracks in polycrystalline nickel. Shahani et al. [19] presented four potential expressions to describe fatigue crack growth rates from $\Delta J, \triangle \mathrm{CTOD}$, $\triangle \mathrm{CMOD}$ and $\Delta K$. They tested several CT specimens made of steel for different values of stress ratio at constant amplitude loading. CMOD was measured using a clip gauge, while $K, J$ and CTOD parameters were computed from equations collected at different ASTM standards. Zhenkun et al. [20] used the crack tip opening angle (CTOA) and the CTOD as fracture parameters to characterise the resistance to fracture of a bi-material cantilever beam test (DCB) composed by a carbon fibre laminate and a piezoelectric ceramic plate and to predict the instability of crack propagating fracture process. They used digital image correlation (DIC) to measure the displacement fields on the specimen surface with an initial interfacial crack. Tagawa et al. [21] investigated crack opening profiles and CTOD in SEN specimens of BS7448 steel by observing unloaded crack tips and silicone rubber replication of loaded crack tips. Deng et al. [22] estimated cyclic CTOD for low-cycle failure analysis on a central-through cracked plate made of Q235 steel by using the plastic strain accumulation at the crack tip as controlling parameter. Dong et al. [23] presented an analytical model which follows a linear correlation between $d a / d N$ and $\Delta$ CTOD. They found a good comparison between predictions and experimental results, which showed that the crack opening displacement was able to characterise the crack tip state at large scale yielding constant amplitude fatigue crack growth. They measured CTOD by using a strain extensometer located on a CT specimen of Q345 steel.

Besides to separately investigate the ability of both parameters to characterise fatigue crack growth, different works [24]-[26] have been reported establishing a relationship between them. Shih [24] obtained a relationship between the $J$-integral and the crack opening displacement by employing the dominance of the Hutchinson-Rice-Rosenberg singularity [27], [28] in the crack tip region. This relationship was corroborated by finite elements results for the complete regime of elastic-plastic deformation and experimental data for A533B steels, HY-80 steels and several other ductile metals. Shih's study was used by Metzger et al. [25] and Sarzosa et al. [26] to numerically show that this $J$-CTOD relationship is valid even in cases where crack closure is present [25] and to establish accurate relationships between $J$ and CTOD for use in testing protocols for toughness measurements [26].

In a previous work, Antunes et al. [29] developed a numerical study to quantify the CTOD on middle-tension (MT) specimens for two aluminium alloys in order to evaluate if this parameter could be used to characterise fatigue crack growth. They found a polynomial relationship between $d a / d N$ and the $\Delta \mathrm{CTOD}_{\mathrm{p}}$ for the 6082-T6 aluminium alloy independent of the stress ratio, showing 
that CTOD can be used as an alternative to $\Delta K$ in analysing fatigue crack propagation. Thus, in the current work DIC is used to quantify experimentally the plastic CTOD in order to implement the procedure developed by Antunes et al. [29] to characterise fatigue crack growth. This way the $d a / d N$ versus plastic CTOD model is obtained experimentally without the need of numerical modelling. Note that the values of $\Delta \mathrm{CTOD}_{\mathrm{p}}$ reported in [29] are relatively small, lower than 1 $\mu \mathrm{m}$, which is a challenge for the experimental determination of the plastic CTOD. In fact, some controversy exits about the ability of DIC to provide extremely high spatial resolution characterisation of crack tip deformation fields, including crack opening profiles [30]. The vertical displacements obtained by DIC on growing fatigue cracks are used to measure the CTOD as the relative displacement existing between the crack flanks. Two fatigue tests at stress ratios of 0.1 and 0.6 were conducted on titanium CT specimens. With this work, the authors intend to check the ability of CTOD to characterise fatigue crack growth and, in this way, to contribute to a better understanding of the mechanisms driving fatigue crack propagation.

\section{Experimental methods}

Two CT specimens (dimensions shown in Figure 2a) manufactured from a $1 \mathrm{~mm}$ thick sheet of commercially pure grade 2 titanium were tested at constant amplitude fatigue loading using two different values of stress ratio ( 0.1 and 0.6 ) whilst maintaining a constant value of the maximum load level $(750 \mathrm{~N})$ in the fatigue cycle. The chemical composition from a typical analysis for this commercially pure titanium grade 2 is presented in Table 1.

For the experimental observation of the two surfaces of each specimen, two different procedures were developed. The surface to be used for implementing DIC was treated by spraying a black speckle with an airbrush over a white background (Figure $2 b$ ), while the other surface was polished to assist in tracking the crack tip with a zoom lens.

Fatigue tests were conducted on an Electropuls E3000 electrodynamic machine (Figure 2) at a loading frequency of $10 \mathrm{~Hz}$. A CCD camera, fitted with a macro-zoom lens (MLH-10X EO) to increase the spatial resolution at the region around the crack tip, was placed perpendicularly to each face of the specimen. During fatigue testing, the cyclic loading was periodically paused to allow acquisition of a sequence of images at uniform increments through a complete loading and unloading cycle. The CCD camera viewing the speckled surface of the specimen was set up so that the field of view was $17.3 \times 13 \mathrm{~mm}$ (resolution of $13.7 \mu \mathrm{m} / \mathrm{pix}$ ) with the crack path located at the centre of the image. A fibre optic ring placed around the zoom lens was provided to illuminate the specimen surface (also shown in Figure 2).

\section{Methodology for locating the crack tip}


As indicated above, the CTOD is a parameter that measures the opening at the crack tip, hence the vertical displacements obtained from experiments are used and analysed for its measurement. An example of horizontal and vertical displacement maps measured with DIC for a crack length of $9.40 \mathrm{~mm}$ and a load level of $750 \mathrm{~N}$ are shown in Figure 3.

The CTOD is obtained by measuring the relative displacement between the crack flanks selecting a pair of points behind the crack tip. According to this, a relevant aspect is the correct location of the crack tip. First, the $y$-coordinate of the crack tip is found by plotting a set of profiles perpendicular to the crack direction employing the vertical displacement map since a change in the profiles is observed when they go through the crack wake. Figure 4a shows that the different profiles plotted around the crack tip intersect at one point which indicates the location of the crack tip in the $y$-direction. The corresponding displacement value for this point has been also indicated because it is used to find the $x$-coordinate of the crack tip. Once the $y$-coordinate of the crack tip has been located, a parallel profile to the crack direction corresponding to the $y$-coordinate previously obtained is plotted. The $x$-coordinate of the crack tip is obtained from the point of the plotted profile which presents the same displacement value than that previously known for the $y$ coordinate. Thus, a horizontal profile corresponding to this displacement value $(v=0.158 \mathrm{~mm})$ is plotted, establishing the $x$-coordinate as the interaction point between both lines as shown in Figure 4b. According to this procedure, the crack tip was located at the point with coordinates $x$ $=470$ pixels and $y=468$ pixels, being the origin of coordinates the upper left corner of the vertical displacement map.

Once the location of the crack tip has been established, the experimental CTOD is obtained by defining the measurement points behind the crack tip. Thus, the CTOD as a function of load for a complete loading cycle is evaluated by analysing both the loading and unloading branches. In this way, the portion of the cycle at which the crack is closed and open can be found. In addition, from the analysis of the portion at which the crack is open, the elastic and plastic components of the CTOD can be estimated from the slope variation observed in the CTOD versus load curves.

\section{Effect of the position behind the crack tip}

A sensitivity analysis was performed to explore the effect of the position of the pair of points selected behind the crack tip for the CTOD measurement. Two parameters define the position of the points behind the crack tip, which are the distances along and perpendicular to the crack. As Figure 5 shows, the distance along the crack is referenced as $L_{x}$, while $L_{y}$ is used for the perpendicular direction to the crack.

This analysis was performed by measuring the CTOD at the maximum load as a function of one of the parameters, maintaining fixed the other parameter. In Figure 6a, the CTOD for different $L_{y}$ distances was plotted as a function of $L_{x}$ distance. It can be observed that the CTOD values are 
higher as the measurement points are moving away from the crack tip, as could be expected. This increase in the CTOD values along the crack is higher as the measurement points are located at larger $L_{y}$ distances. Moreover, it is observed that for a same $L_{x}$ value, CTOD is gradually increasing until reaching a stable value from $L_{y}=10$ pixels $(136.9 \mu \mathrm{m})$. This last observation can be more easily analysed by plotting the CTOD as a function of the perpendicular distance $L_{y}$ to the crack direction (fixing $L_{x}$ ). Figure $6 \mathrm{~b}$ clearly shows that, for a same $L_{x}$ location, the CTOD gradually increases until reaching a stable value at the $L_{y}$ distance indicated above. The region at which stable values of CTOD were obtained has been marked inside a rectangle. This region encloses the values obtained for CTOD corresponding to the ranges 5-15 pixels (68.4-205.3 $\mu \mathrm{m})$ for $L_{x}$ and 10-15 pixels (136.8-205.3 $\left.\mu \mathrm{m}\right)$ for $L_{y}$. According to this analysis, all results presented hereafter were obtained using a value of 5 pixels $(68.4 \mu \mathrm{m})$ for $L_{x}$ and 10 pixels $(136.8 \mu \mathrm{m})$ for $L_{y}$.

From the analysis above it can be established that the CTOD value significantly depends of the location along the crack of the points selected behind the crack tip. However, the effect of the perpendicular distance to the crack direction is not so restrictive since it has been observed that from 10 pixels $(136.9 \mu \mathrm{m})$ a stable value of CTOD was obtained.

\section{Experimental results}

Once the values of $L_{x}$ and $L_{y}$ distances were established, the evolution of CTOD with loading for a particular crack length was analysed. A typical plot of CTOD along a full loading cycle for the crack length analysed above ( $a=9.40 \mathrm{~mm}$ ) is shown in Figure 7, where the separation existing between every data-point corresponds to a load of $25 \mathrm{~N}$. From the analysis of the loading and unloading branches, the elastic and plastic components can be identified. For this, a procedure similar to that reported by Skorupa et al. [31] based on compliance measurement has been employed. A least squares straight line was fitted to experimental data at the part of the loading cycle which is attributed to the elastic deformation. To define this portion of the cycle, a segment that spans a range between $20 \%$ and $60 \%$ of the loading range was selected. The equation obtained from this linear fit was employed to calculate the theoretical CTOD value corresponding to all analysed load levels. Thus, the CTOD offset was obtained from the following expression:

$$
\text { CTOD offset }=\frac{\text { CTOD }_{\text {th }}-C T O D_{\text {exp }}}{C T O D_{t h}} \cdot 100
$$

Finally, the CTOD offset was plotted as a function of the applied load (Figure 8) to identify the elastic and plastic components of the CTOD present in the $P$-CTOD curve plotted in Figure 7. A value of $4 \%$ according to the standard E 647 [32] was used as offset criterion (marked in Figure 8) to establish the region associated with the elastic deformation. The different regions observed from the analysis of the CTOD data along the loading cycle have been marked by letters in both 
figures. According to this, the region $B-C$ corresponding to a load range between $175 \mathrm{~N}$ and 450 $\mathrm{N}$ (with offset values lower than $5 \%$ ) was established to define the elastic behaviour. This region corresponds to the linear part of the curve in Figure 7. In addition, it is observed in Figure 7 that from point $\mathrm{C}$ there is a change in the linearity until reaching point $D$, corresponding to the maximum applied load, which is attributed to the plastic deformation. Thus, the elastic and plastic ranges of CTOD can be estimated by extrapolating the linear regime to the maximum load as it is observed in Figure 7. During unloading, there is a linear decrease between points $D$ and $E$ with the same slope than that obtained for the elastic regime in the loading branch. Again, as in the case of the loading branch, there is a change in the linearity due to the reversed plastic deformation. Therefore, the same procedure indicated for the loading branch can be used to estimate the elastic and plastic ranges of CTOD. According to this, during loading the elastic and plastic ranges of CTOD obtained were $13 \mu \mathrm{m}$ and $6 \mu \mathrm{m}$, respectively. On the other hand, during unloading the values for the ranges of the elastic and plastic components were $13.2 \mu \mathrm{m}$ and 5.8 $\mu \mathrm{m}$, respectively. The values obtained for the plastic component correspond to a percentage respect to the total CTOD of $31.6 \%$ and $30.5 \%$ for the loading and unloading branches, respectively.

Moreover, the region between points $A$ and $B$ in Figures 7 and 8 is associated with the portion of the loading range at which the crack moves from fully closed to fully open. An additional study could be performed to estimate the opening or closing loads, but this goes further to the main objective of the present work.

The methodology described above to obtain the CTOD range for the elastic and plastic components was applied at all the analysed crack lengths for the two tests conducted. Figure 9a shows the elastic and plastic CTOD ranges as a function of the crack length. A scatter is observed for the elastic component values, while the values for the plastic component show a gradual increment with the crack length. This increment is progressively higher with the crack length in the case of the test conducted at low stress ratio. Besides analysing the evolution of both components with crack length, it is also interesting to analyse them from a relative point of view. In this way, the percentage represented by each component with respect to the total CTOD was plotted in Figure 9b. Realignment for the elastic values is clearly observed, decreasing gradually with the crack length. In the same way, an overlap for the plastic component values is obtained, with a progressive increment along the crack length. This behaviour observed for both components is not surprising since as a crack is propagating, the plastic deformation is increasing and, with it, the plastic component. In addition, the behaviour of the elastic component is opposite to that observed for the plastic component. This behaviour observed for the plastic component highlights that it can be linked to the plastic deformation generated during the crack propagation. In order to highlight this assertion, $d a / d N$ as a function of $\Delta \mathrm{CTOD}_{\mathrm{t}}, \Delta \mathrm{CTOD}_{\mathrm{el}}$ and $\Delta \mathrm{CTOD}_{\mathrm{p}}$ for 
the specimen tested at $R=0.1$ was plotted in Figure 10. It is clearly observed that only the plastic component of CTOD seems to show a linear variation with crack growth per cycle. According to this, only the plastic component of CTOD is relevant to characterise fatigue crack growth. Finally, Figure 11 shows the $d a / d N$ versus $\Delta \mathrm{CTOD}_{\mathrm{p}}$ curves obtained for the two tested specimens. It has to be noted that this graph was obtained without employing a logarithmic scale as in the case of Paris law. An overlap of the results for both specimens was obtained, with a linear variation between $d a / d N$ and $\Delta \mathrm{CTOD}_{\mathrm{p}}$. Thus, a straight line was fitted by a linear regression:

$$
\frac{d a}{d N}=0.2706 \times \Delta C T O D_{p}
$$

This relationship is independent to the stress ratio applied to conduct the fatigue test and it could constitute a property of the analysed material. In addition, the constant in Eq. (2) does not have units unlike the constants defined by Paris law. The linear relationship between $d a / d N$ and $\Delta$ CTOD was also observed by Guo et al. [33], Tvergaard [34] and Pippan and Grosinger [35]. However, all those works used the total CTOD and they did not make any distinction of the CTOD components. Moreover, this linear relationship between $d a / d N$ and $\Delta \mathrm{CTOD}_{\mathrm{p}}$ was reported by Antunes et al. [36] on 7050-T6 aluminium alloy $\left(d a / d N=0.5246 \cdot \Delta \mathrm{CTOD}_{\mathrm{p}}\right)$ in a numericalexperimental work recently published. They obtained the $d a / d N$ data from experiments in MT specimens for different stress ratios and the plastic CTOD data were numerically determined by using their methodology previously reported in [29]. However, the work presented here is purely experimental where the $d a / d N$ data were obtained from the measurements of crack length and the number of cycles collected during the fatigue tests and the CTOD data were obtained from the analysis of the vertical displacement measured by DIC, a full-field optical technique very recognised and accepted within the scientific community [37]. Therefore, it is believed that it is the first time that a purely experimental characterisation of fatigue crack growth based on the plastic component of the CTOD was performed.

\section{Conclusions}

The plastic component of CTOD was linked with the plastic deformation generated at the crack tip during fatigue crack propagation at constant amplitude. Therefore, the range of plastic CTOD $\left(\triangle \mathrm{CTOD}_{\mathrm{p}}\right)$ was used to experimentally characterise fatigue crack growth. A linear relationship between $d a / d N$ and $\Delta \mathrm{CTOD}_{\mathrm{p}}$ independent of stress ratio was obtained on two $\mathrm{CT}$ titanium specimens tested at $R$-ratios of 0.1 and 0.6. The elastic and plastic components of CTOD were determined by analysing the CTOD plot along a full loading cycle. The CTOD was measured as the relative displacement existing between the crack flanks by using the vertical displacements obtained by DIC. A sensitivity analysis to explore the effect of the position of the points selected behind the crack tip was performed. It was observed that the CTOD value depends significantly 
of the location of the points along the crack direction. However, the effect of the perpendicular distance to the crack direction is not so restrictive since from a particular distance (136.9 $\mu \mathrm{m})$, a stable value of CTOD was obtained. In addition, as CTOD is measured by selecting a pair of points behind the crack tip, a relevant aspect is its correct location. According to this, a methodology to locate the coordinates of the crack tip was presented by analysing different profiles plotted from the vertical displacement map.

This work demonstrated that CTOD could represent a viable alternative to stress intensity factor to characterise fatigue crack growth since CTOD considers fatigue threshold and crack shielding in an intrinsic way [36]. However, further work is necessary to explore if the linear relationship obtained between $d a / d N$ and $\Delta \mathrm{CTOD}_{\mathrm{p}}$ may be considered as a property of the material and independent to the geometry and the loading conditions. Thus, the authors are working on additional experimental and numerical-experimental investigations in different materials, different specimen geometries and fatigue crack growth at variable amplitude loading conditions.

\section{Acknowledgements}

This work has been conducted with financial support from Gobierno de España through the project "Proyecto de Investigación de Excelencia del Ministerio de Economía y Competitividad MAT2016-76951-C2-1-P". 


\section{References}

[1] P.C. Paris, M.P. Gomez, W.P. Anderson, A rational analytic theory of fatigue, The Trend in Engineering13, 9-14 (1961).

[2] P.C. Paris, F. Erdogan, A critical analysis of crack propagation laws, Journal of Basic Engineering 85, 528-534 (1963).

[3] J.R. Rice, A path independent integral and the approximate analysis of strain concentrations by notches and cracks, Journal of Applied Mechanics 35, 369-386 (1968).

[4] J.D. Eshelby, The continuum theory of lattice defects, In Progress in Solid State Physics 3 pp. 79-144 (1956), Academy Press, New York.

[5] J.L. Sanders, On the Griffith-Irwin fracture theory, Journal of Applied Mechanics 27, 352353 (1960).

[6] G.P. Cherepanov, On crack propagation in solids, International Journal of Solids and Structures 5, 863-871 (1969).

[7] N.E. Dowling, J.A. Begley, Fatigue crack growth during gross plasticity and the J-integral, In Mechanics of Crack Growth, Special Technical Publication 590, pp. 82-103 (1976), Philadelphia: American Society for Testing and Materials.

[8] K. Sadananda, P. Shahinian, A fracture mechanics approach to high temperature fatigue crack growth in Udimet 700, Engineering Fracture Mechanics 11, 73-86 (1979).

[9] D.F. Mowbray, Use of a compact-type strip specimen for fatigue crack growth rate testing in the high-rate regime, ASTM STP 668, 736-752 (1979).

[10] M.H. El-Haddad, B. Mukherjee, Elastic-plastic fracture mechanics analysis of fatigue crack growth, ASTM STP 803, 736-752 (1983).

[11] M. Jolles, Effects of load gradient on applicability of a fatigue crack growth rate-cyclic $J$ relation, ASTM STP 868, 381-391 (1985).

[12] L. Banks-Sills, Y. Volpert, Application of the cyclic J-integral to fatigue crack propagation of Al 2024-T351, Engineering Fracture Mechanics 40(2), 355-370 (1991).

[13] A.A. Wells, Unstable crack propagation in metals: Cleavage and fast fracture, In Proceedings of the Crack Propagation Symposium 1, Paper 84 (1961), Cranfield, United Kingdom.

[14] C. Laird, G.C. Smith, Crack propagation in high stress fatigue, Philosophical Magazine 8, 847-857 (1962).

[15] R.M.N. Pelloux, Crack extension by alternating shear, Engineering Fracture Mechanics 1, 697-704 (1970).

[16] R.J. Donahue, H.M. Clark, P. Atanmo, R. Kumble, A.J. McEvily, Crack opening displacement and the rate of fatigue crack growth, International Journal of Fracture Mechanics 8(2), 209-219 (1972). 
[17] D.J. Nicholls, The relation between crack blunting and fatigue crack growth rates, Fatigue and Fracture of Engineering Materials and Structures 17, 459-467 (1994).

[18] A. Weidner, W. Tirschler, C. Blochwitz, Overstraining effects of the crack-opening displacement of microstructurally short cracks, Materials Science and Engineering A 390, 414-422 (2005).

[19] A.R. Shahani, H.M. Kashani, M. Rastegar, M.B. Dehkordi, A unified model for the fatigue crack growth rate in variable stress ratio, Fatigue and Fracture of Engineering Materials and Structures 32, 105-118 (2009).

[20] L. Zhenkun, B. Ruixiang, D. Libo, Q. Wei, Noncontact optical measurement of CTOA and CTOD for interface crack in DCB test, Optics and Lasers in Engineering 50, 964-970 (2012).

[21] T. Tagawa, T. Kawabata, T. Sakimoto, Y. Kayamori, M. Ohata, Y. Yamashita, E. Tamura, H. Yoshinari, S. Aihara, F. Minami, H. Mimura, Y. Hagihara, Experimental measurements of deformed crack tips in different yield-to-tensile ratio steels, Engineering Fracture Mechanics 128, 157-170 (2014).

[22] J. Deng, P. Yang, Q. Dong, D. Wang, Research on CTOD for low-cycle fatigue analysis of central-through cracked plates considering accumulative plastic strain, Engineering Fracture Mechanics 154, 128-139 (2016).

[23] Q. Dong, P. Yang, G. Xu, J. Deng, Mechanisms and modeling of low cycle fatigue crack propagation in a pressure wessel steel Q345, International Journal of Fatigue 89, 2-10 (2016).

[24] C.F. Shih, Relationships between the $J$-integral and the crack opening displacement for stationary and extending cracks, Journal of the Mechanics and Physics of Solids 29, 305326 (1981).

[25] M. Metzger, T. Seifert, C. Schweizer, Does the cyclic $J$-integral $\Delta J$ describe the crack-tip opening displacement in the presence of crack closure? Engineering Fracture Mechanics 134, 459-473 (2015).

[26] D.F.B. Sarzosa, R.F. Souza, C. Ruggieri, J-CTOD relations in clamped SE(T) fracture specimens including 3-D stationary and growth analysis, Engineering Fracture Mechanics 147, 331-354 (2015).

[27] J.W. Hutchinson, Singular behavior at the end of a tensile crack in a hardening material, Journal of the Mechanics and Physics of Solids 16, 13-31 (1968).

[28] J.R. Rice, G.F. Rosengren, Plane strain deformation near a crack tip in a power law hardening material, Journal of the Mechanics and Physics of Solids 16, 1-12 (1968).

[29] F.V. Antunes, S.M. Rodrigues, D. Camas, A numerical analysis of CTOD in constant amplitude fatigue crack growth, Theoretical and Applied Fracture Mechanics 85, 45-55 (2016). 
[30] A.M. Korsunsky, X. Song, J. Belnoue, T. Jun, F. Hofmann, P.F.P. de Matos, D. Nowell, D. Dini, O. Aparicio-Blanco, M.J. Walsh, Crack tip deformation fields and fatigue crack growth rates in Ti-6Al-4V, International Journal of Fatigue 31, 1771-1779 (2009).

[31] M. Skorupa, S. Beretta, M. Carboni, T. Machniewicz, An algorithm for evaluating crack closure from compliance measurements, Fatigue and Fracture of Engineering Materials and Structures 25, 261-273 (2002).

[32] E 647-00, Standard Test Method for Measurement of Fatigue Crack Growth Rates, Philadelphia: American Society for Testing and Materials, 2000.

[33] W. Guo, C. H. Wang, L.R.F. Rose, The influence of cross-sectional thickness on fatigue crack growth, Fatigue and Fracture of Engineering Materials and Structures 22, 437-444 (1999).

[34] V. Tvergaard, On fatigue crack growth in ductile materials by crack-tip blunting, Journal of the Mechanics and Physics of Solids 52, 2149-2166 (2004).

[35] R. Pippan, W. Grosinger, Fatigue crack closure: From LCF to small scale yielding, International Journal of Fatigue 46, 41-48 (2013).

[36] F.V. Antunes, R. Branco, P.A. Prates, L. Borrego, Fatigue crack growth modelling based on CTOD for the 7050-T6 alloy, Fatigue and Fracture of Engineering Materials and Structures 40, 1309-1320 (2017).

[37] M.A. Sutton, J.J. Orteu, H.W. Schreier, Image Correlation for Shape, Motion and Deformation Measurements: Basics Concepts, Theory and Applications, Springer Science + Business Media, New York, USA, 2009. 


\section{Figures}
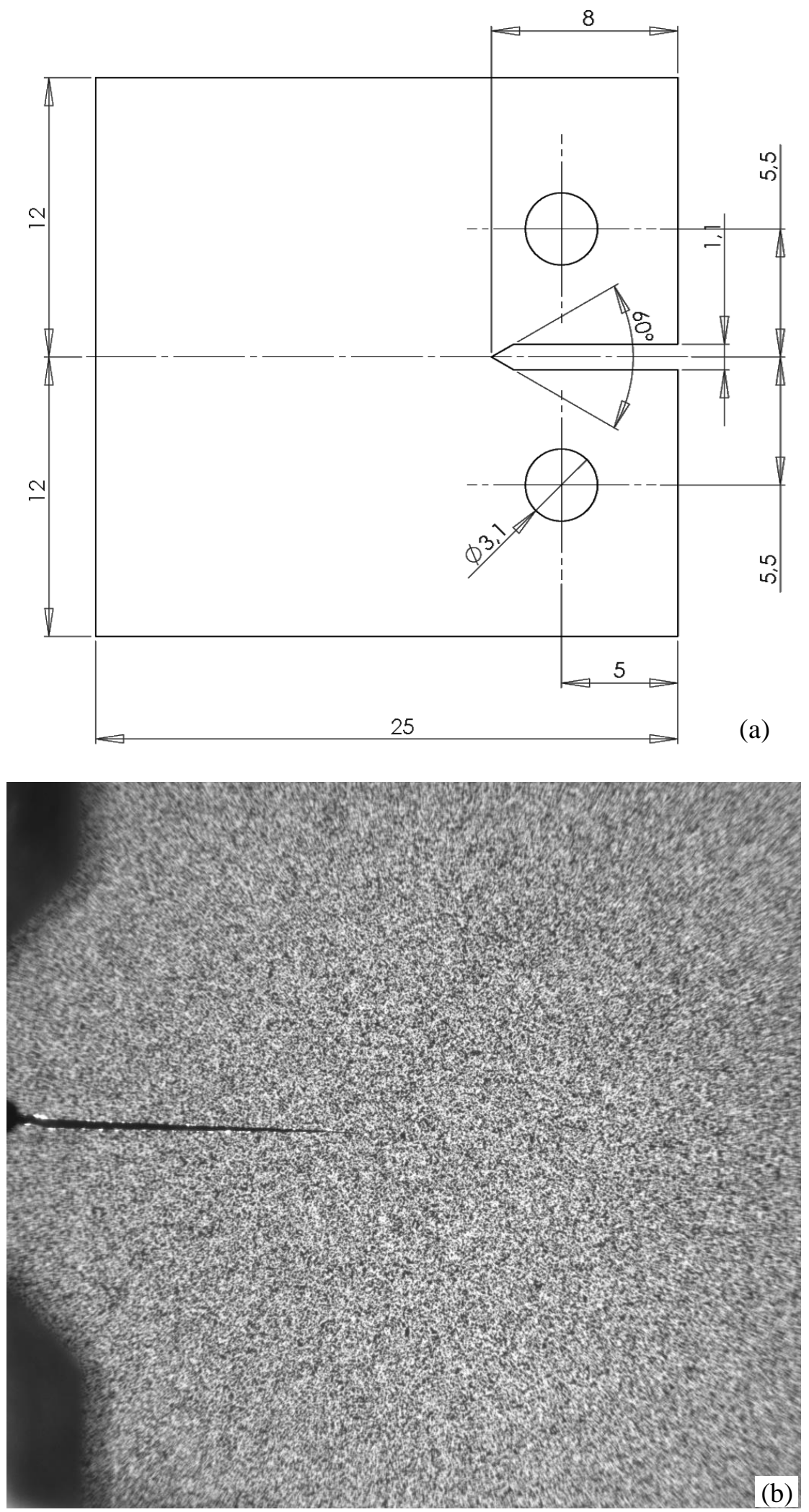

Figure 1 Dimensions in mm of the CT specimens tested. (b) Speckle sprayed on the specimen surface used to implement DIC. 


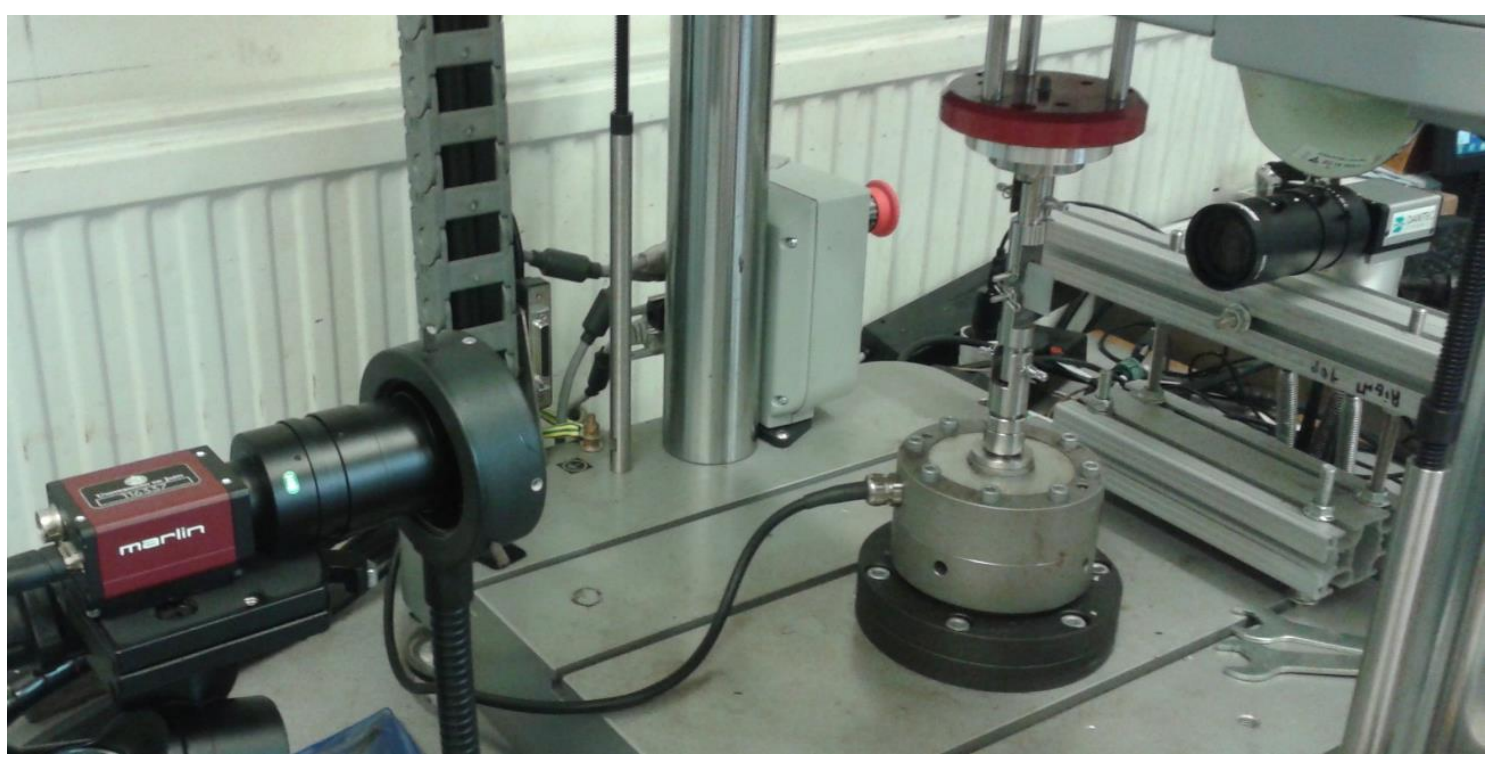

Figure 2 Experimental set-up used to implement DIC during fatigue testing. 

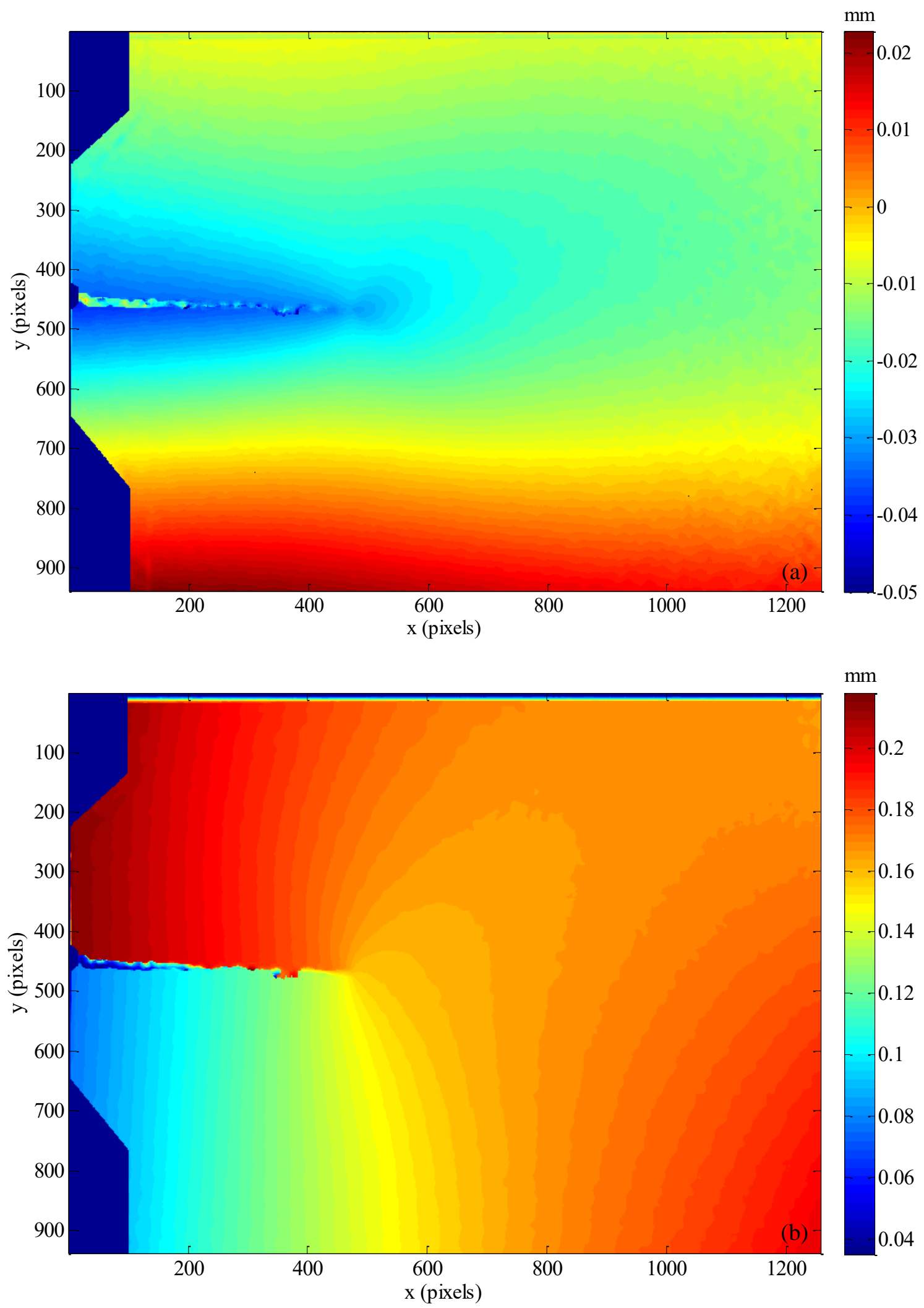

Figure 3 (a) Horizontal and (b) vertical displacement fields measured with DIC for a crack length of $9.40 \mathrm{~mm}$ at a load level of $750 \mathrm{~N}$. 

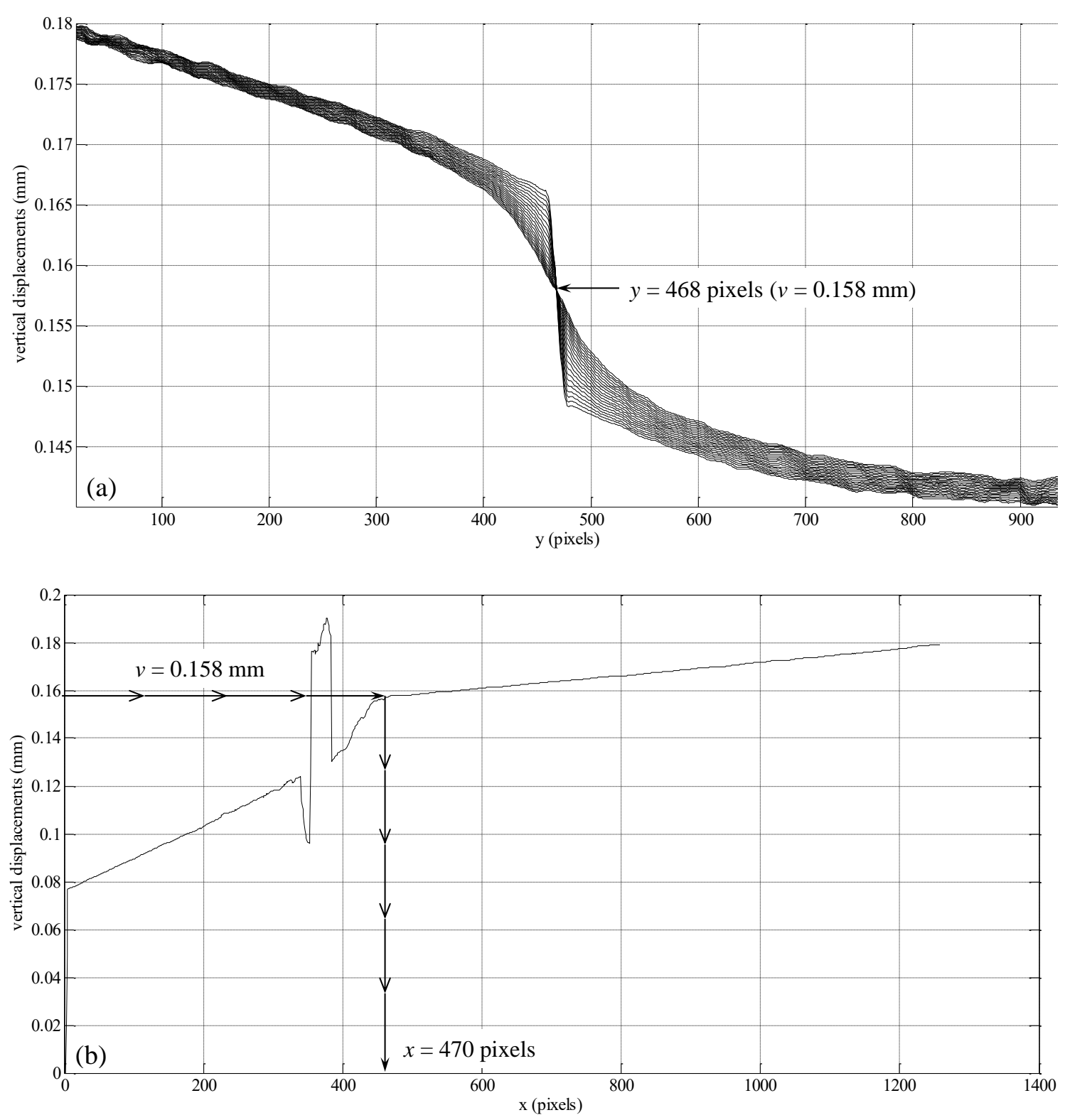

Figure 4 Methodology for locating the crack tip: (a) $y$-coordinate and (b) $x$-coordinate. 


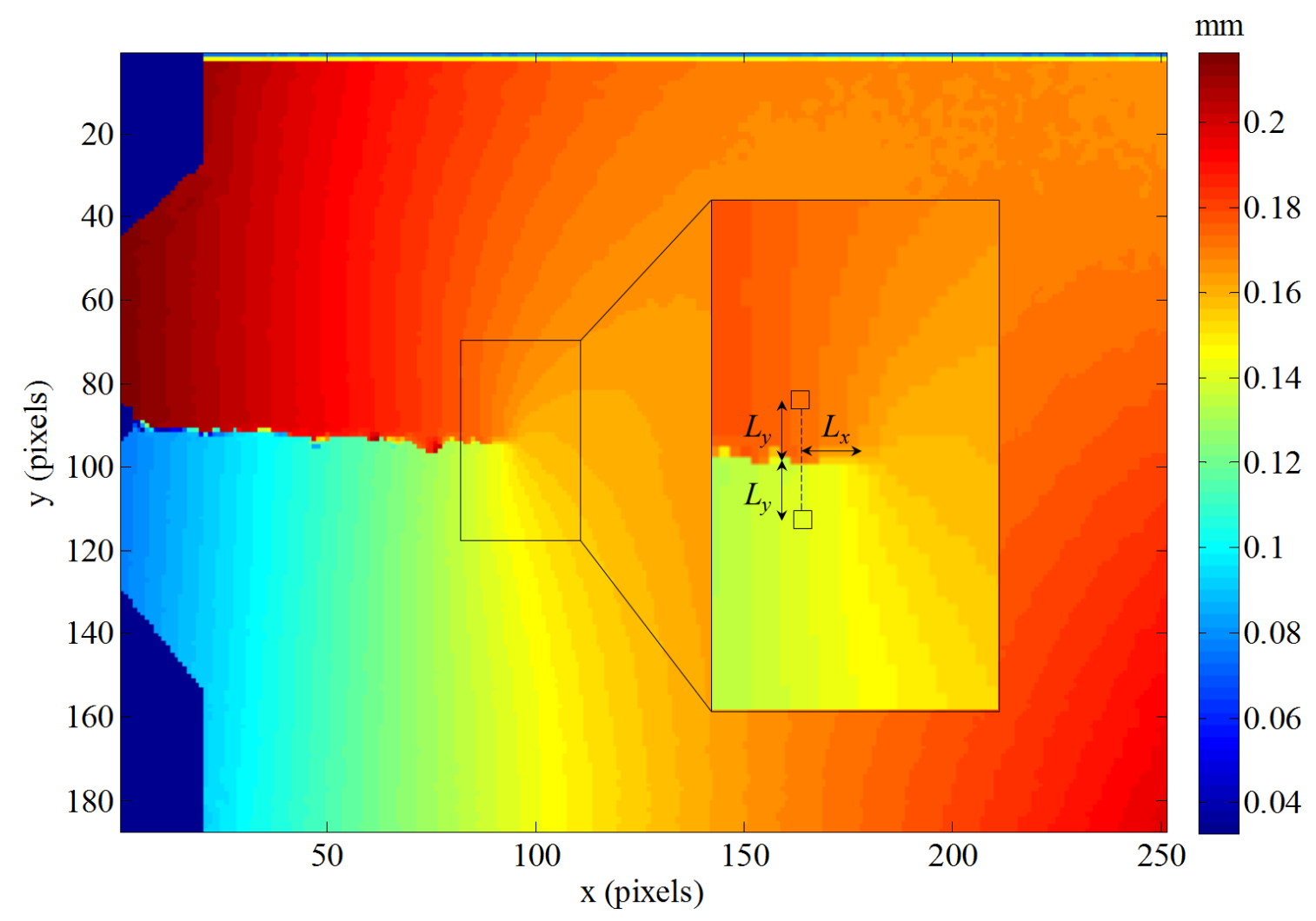

Figure 5 Magnification of the region around the crack tip showing a pair of points behind the crack tip selected for the CTOD measurement. 

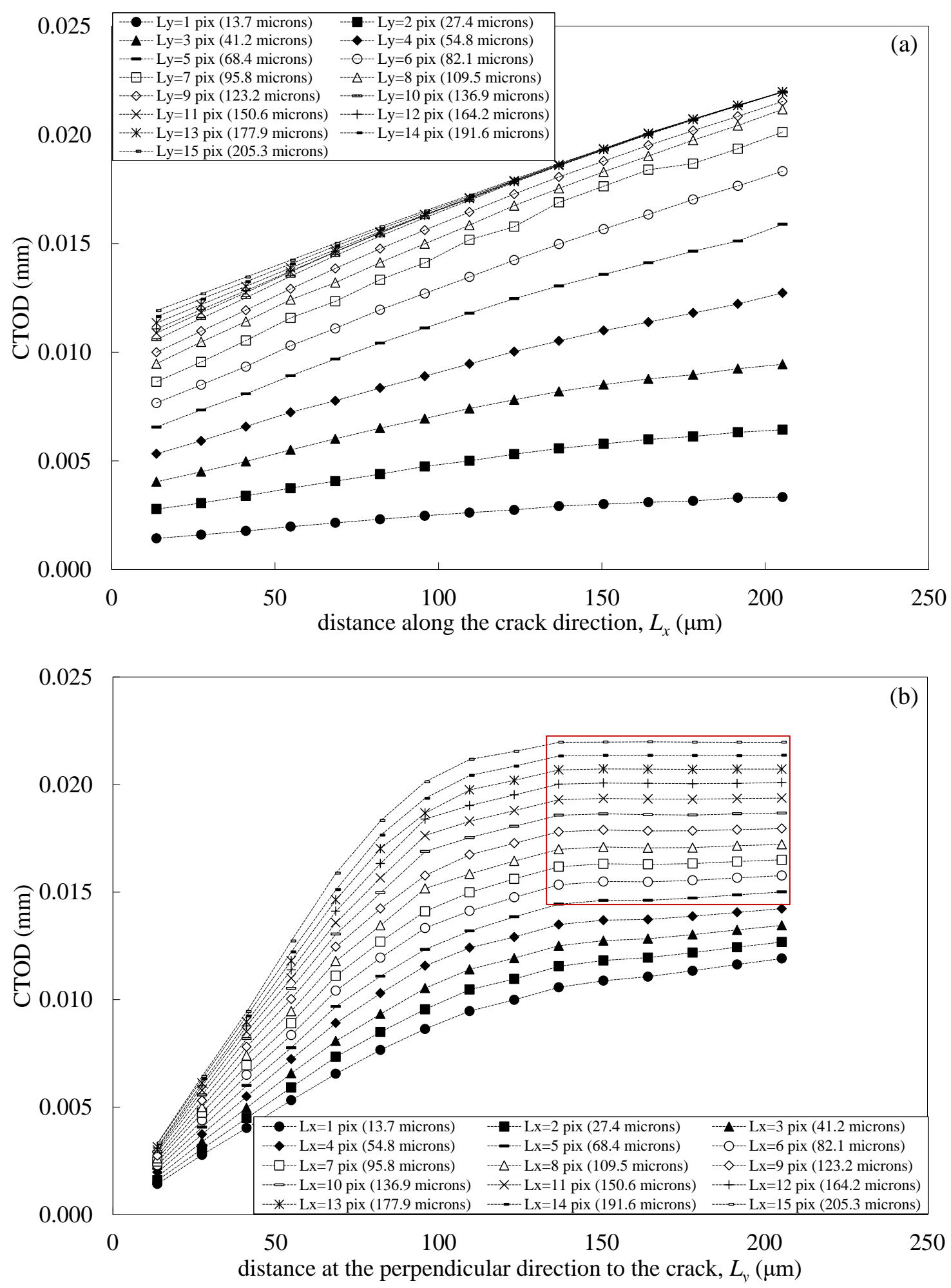

Figure 6 Graphs showing the effect of the location behind the crack tip of the selected points for the CTOD measurement. (a) CTOD as a function of the distance along the crack direction $L_{x}$; (b) CTOD as a function of the distance at the perpendicular direction $L_{y}$ to the crack. 


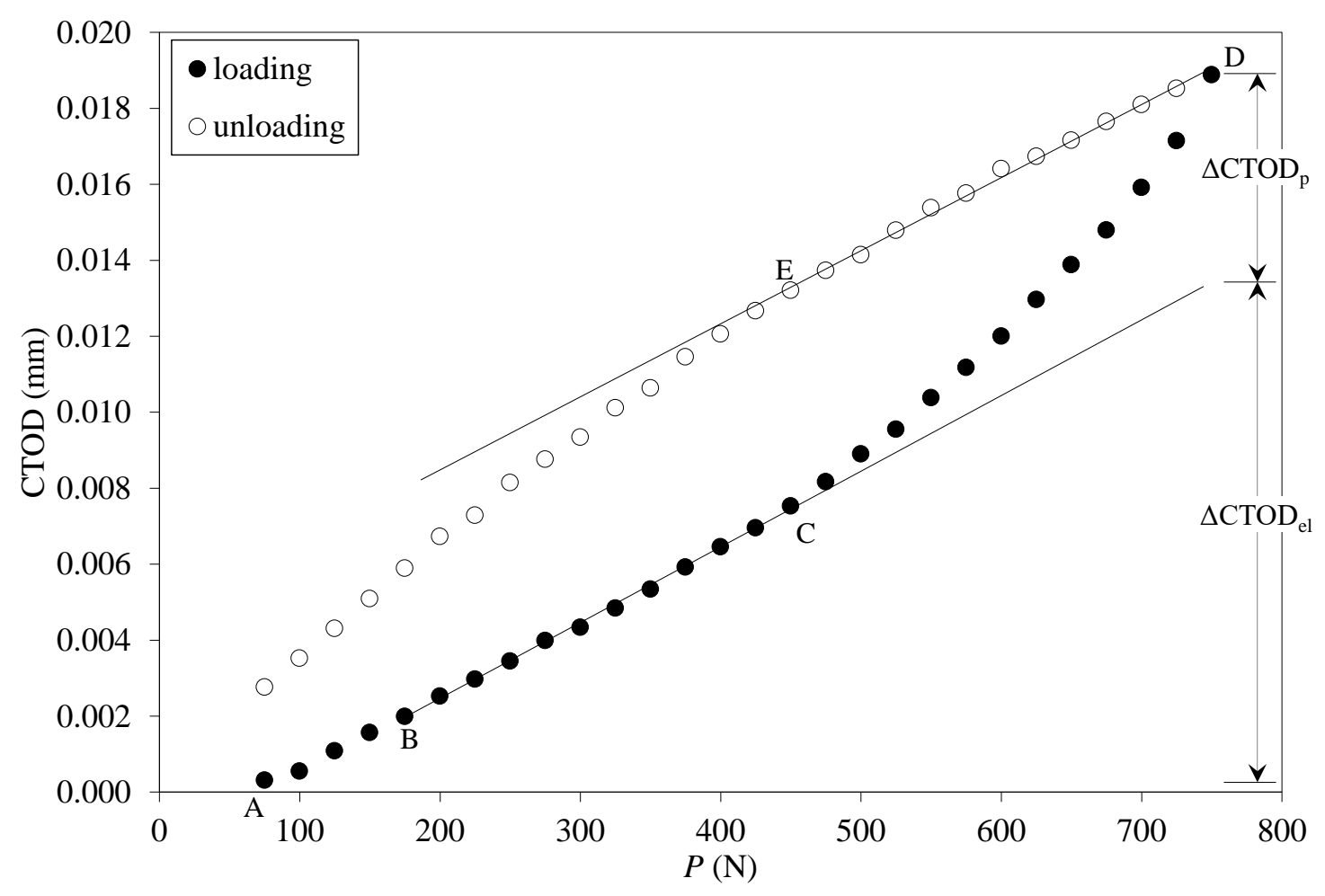

Figure 7 Plot of CTOD along a full loading cycle indicating its elastic and plastic components at a crack length of $9.40 \mathrm{~mm}$ using 5 pixels $(68.4 \mu \mathrm{m})$ and 10 pixels $(136.8 \mu \mathrm{m})$ for the distances $L_{x}$ and $L_{y}$, respectively. 


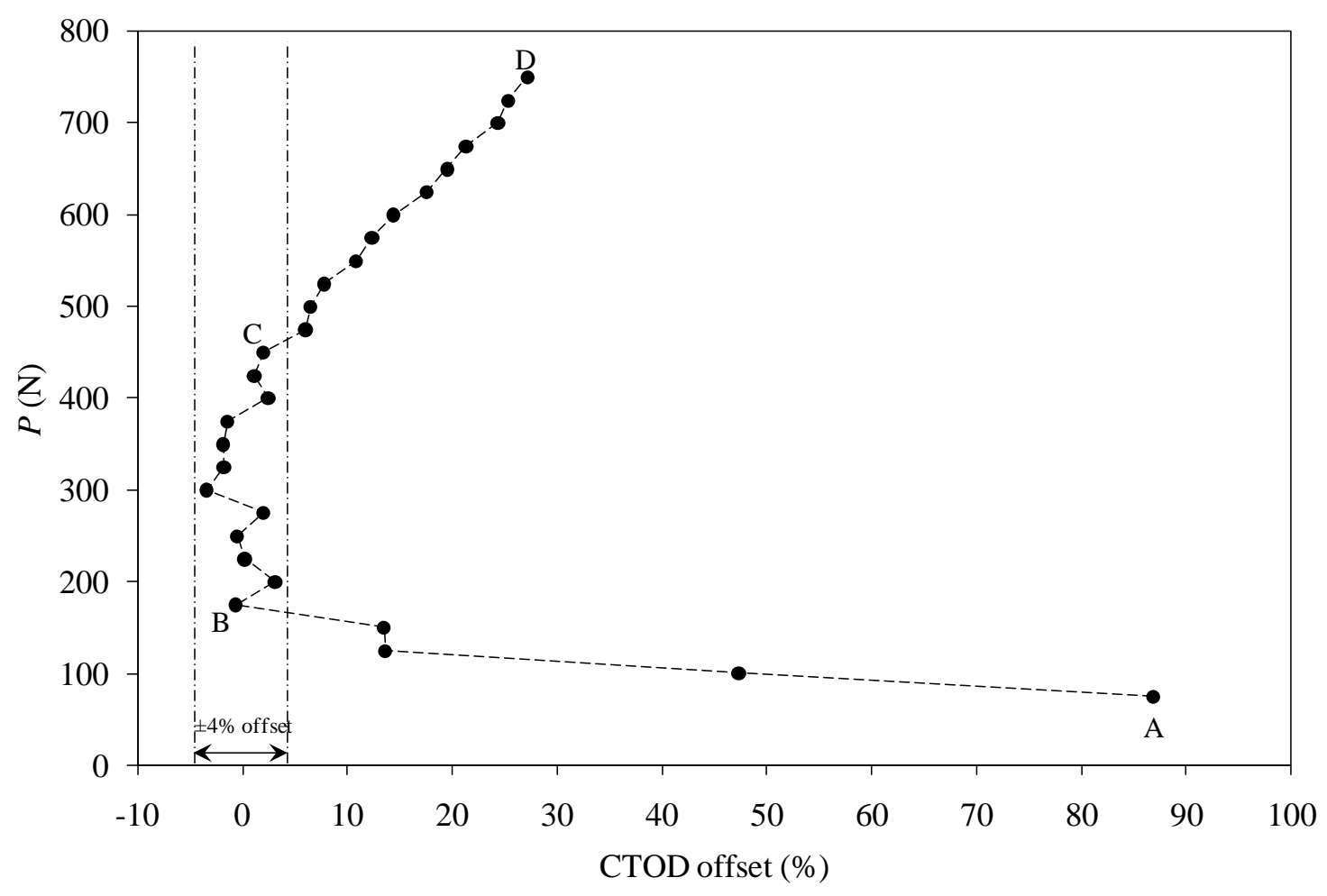

Figure 8 Variation of CTOD offset as a function of the applied load corresponding to the loading branch for a crack length of $9.40 \mathrm{~mm}$. A value of $4 \%$ was established as offset criterion to find the region corresponding to the elastic component of the CTOD. 

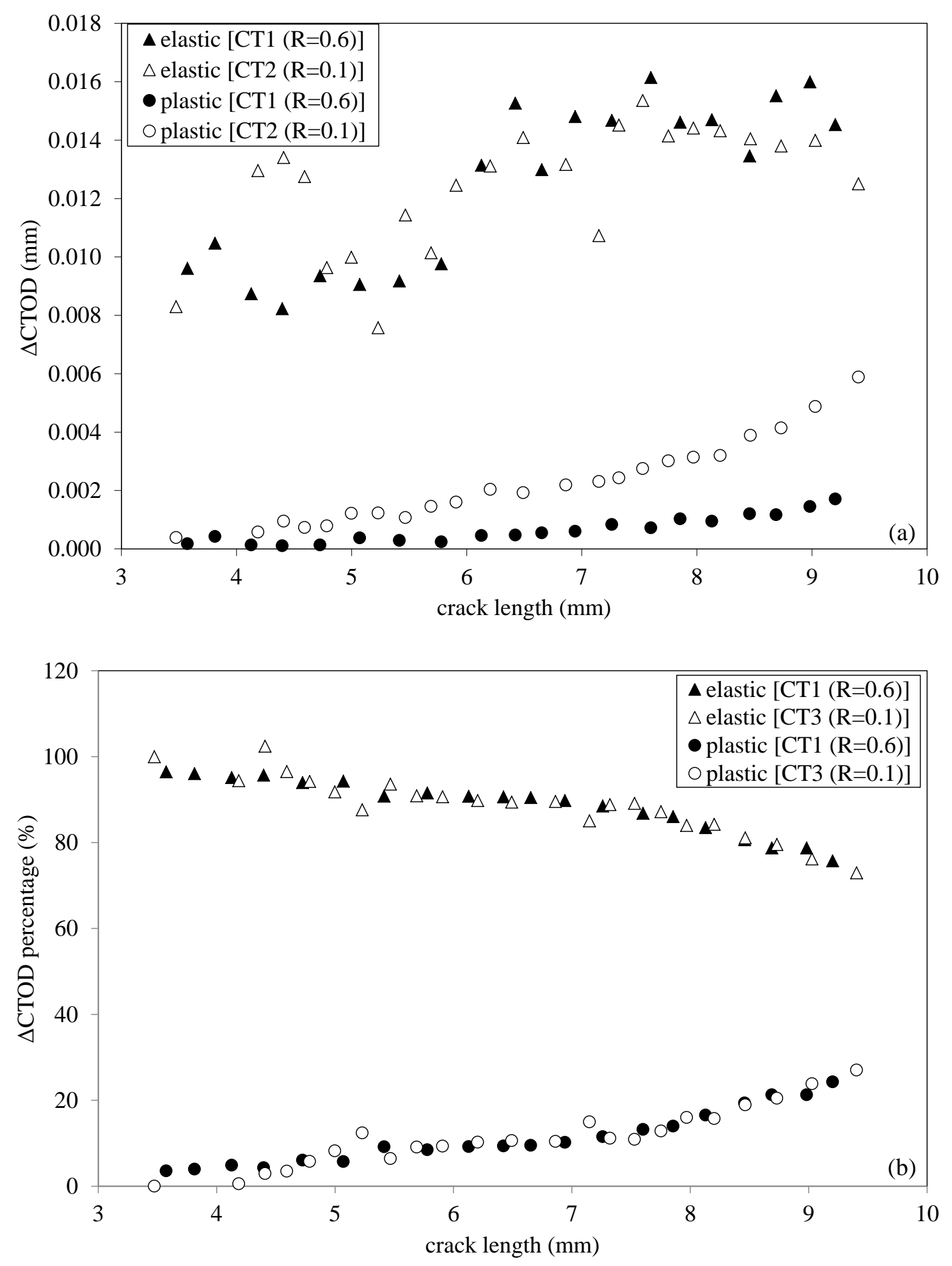

Figure 9 (a) Elastic and plastic DTOD ranges as a function of the crack length for both tests.

(b) Percentage of the elastic and plastic CTOD ranges along the crack length for both tests. 


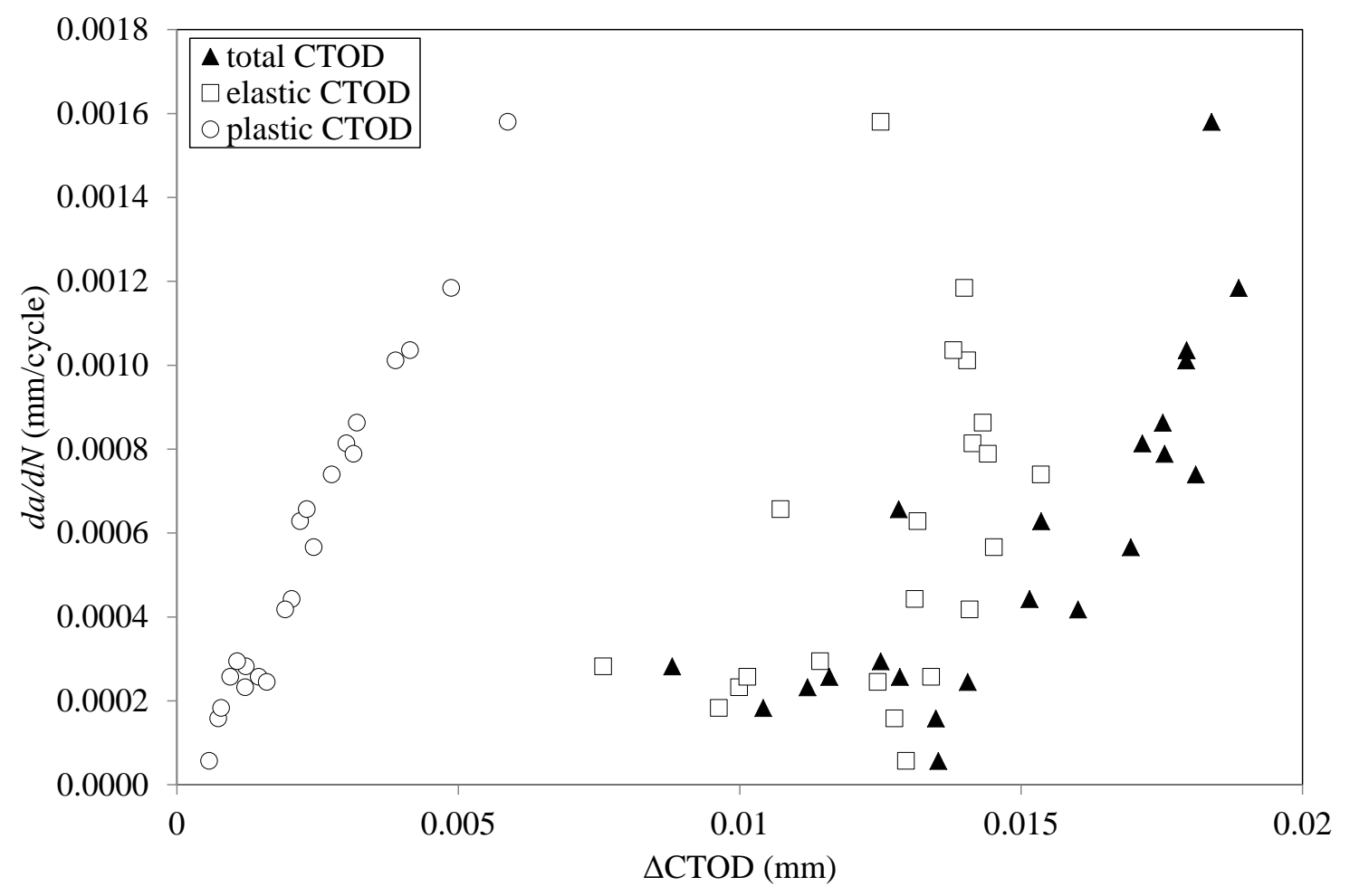

Figure 10 Crack growth per cycle $(d a / d N)$ as a function of the range of total CTOD $\left(\Delta \mathrm{CTOD}_{\mathrm{t}}\right)$, elastic CTOD $\left(\Delta \mathrm{CTOD} \mathrm{D}_{\mathrm{el}}\right)$ and plastic $\mathrm{CTOD}\left(\Delta \mathrm{CTOD}_{\mathrm{p}}\right)$ for the specimen tested at low stress ratio $(R=0.1)$. 


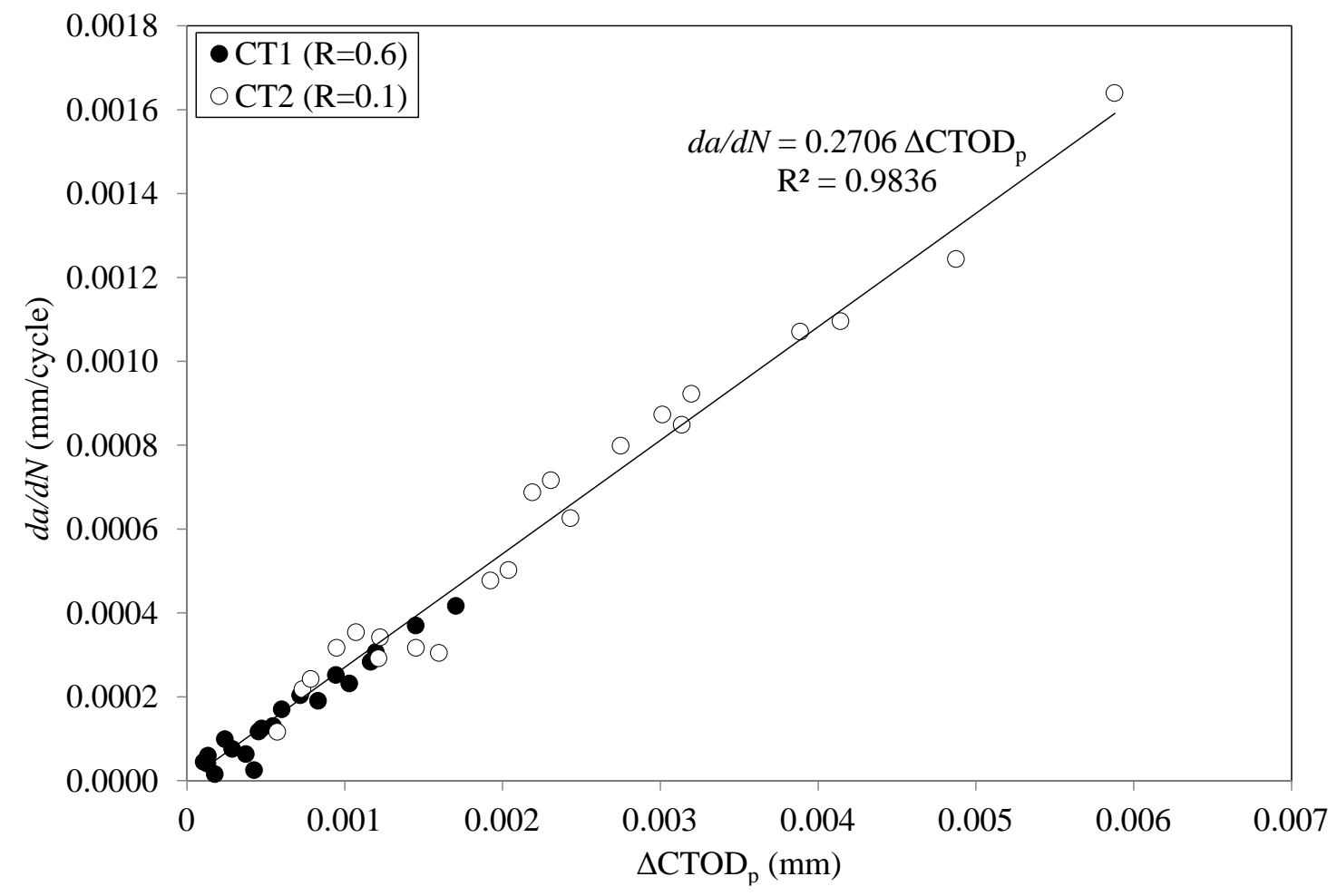

Figure $11 d a / d N$ vs. $\Delta$ CTOD $_{\mathrm{p}}$ curves for both tests conducted at low $(R=0.1)$ and high $(R=$ $0.6)$ stress ratio. 


\section{Tables}

Table 1 Chemical composition for commercially pure titanium grade 2 .

\begin{tabular}{|c|c|c|c|c|c|c|}
\hline Element & Nitrogen & Carbon & Hydrogen & Iron & Oxygen & Titanium \\
\hline $\begin{array}{c}\text { Spec. } \\
\text { wt\% }\end{array}$ & $\leq 0.05$ & $\leq 0.08$ & $\leq 0.015$ & $<0.20$ & $\leq 0.20$ & balance \\
\hline Actual wt\% & $<0.01$ & 0.01 & 0.002 & 0.10 & 0.12 & balance \\
\hline
\end{tabular}

1. Paris, P.C.G., M.P.; Anderson, W.E., A rational theory of of fatigue. Trend Engineering, 1961. 13: p. 9-14.

2. Paris, P.C.E., F., A critical analysis of crack propagation laws. Journal of Basic Engineering, 1963. 85(4): p. 528-534.

3. Hosseini, Z.S., et al., On the theoretical modeling of fatigue crack growth. Journal of the Mechanics and Physics of Solids, 2018. 121: p. 341-362.

4. James, M.N., et al., Local crack plasticity and its influences on the global elastic stress field. International Journal of Fatigue, 2013. 46: p. 4-15.

5. Christopher, C.J., et al., Towards a new model of crack tip stress fields. International Journal of Fracture, 2008. 148(4): p. 361-371.

6. Vasco-Olmo, J.M., et al., Crack tip plastic zone evolution during an overload cycle and the contribution of plasticity-induced shielding to crack growth rate changes. Fatigue and Fracture of Engineering Materials and Structures, 2018. submitted.

7. Vasco-Olmo, J.M., et al., Assessment of Crack Tip Plastic Zone Size and Shape and its Influence on Crack Tip Shielding. Fatigue \& Fracture of Engineering Materials \& Structures, 2016. 39(8): p. 969-981.

8. Yang, B., et al., A more effective rationalisation of fatigue crack growth rate data for various specimen geometries and stress ratios using the CJP model. International Journal of Fatigue, 2018. submitted.

9. Wells, A.A. Unstable Crack Propagation in Metals-Cleavage and Fast Fracture. in Crack Propagation Symposium. 1961. Cranfield: College of Aeronautics, Cranfield.

10. Burdekin, F.M.S., D.E.W., The Crack-Opening-Displacement Approach to Fracture Mechanics in Yielding. Journal of Strain Analysis, 1966. 1(2): p. 145-153.

11. Laird, C.S., G. C., Crack propagation in high stress fatigue. The Philosophical Magazine: A Journal of Theoretical Experimental and Applied Physics, 1962. 7(77): p. 847-857. 